\title{
Ultraviolet-A 'blacklight' fails to serve as a useful survey tool for great crested newt (Triturus cristatus) in ponds
}

\author{
ERIK PATERSON
}

205 Telford Road, East Kilbride, Scotland, G75 0DG, UK

Author e-mail: erikpaterson@virginmedia.com

G reat crested newts (Triturus cristatus) are offered the highest level of protection throughout their range, owing to their listing as an Annex II species of conservation concern within the Habitats Directive (Council Directive 92/43/EEC). In Scotland, this is translated in to law by the Conservation (Natural Habitats, \&c.) Regulations 1994 (as amended) which imposes a duty for the statutory nature conservation organisation, Scottish Natural Heritage, to maintain the favourable conservation status of this, and other Annex II species. Great crested newts are offered the same level of protection in England and Wales, though there are legislative differences.

Perhaps the way in which this statutory obligation is most commonly encountered is within an ecological consultancy environment. Wherein the presence of great crested newts within proximity to development proposals requires surveys by a licensed ecologist to inform mitigation requirements that can maintain or promote favourable conservation status of the species (English Nature, 2001).

One of the most efficient methods for detecting great crested newts is the illumination of a pond by torchlight (Griffiths et al., 1996 \& Kröpfli et al., 2010). However, torchlight surveys using white light often result in movement of great crested newts which could impact upon the reliability of counts by promotion of double counts (e.g. if the newt moves from one side of the pond to another and is doublecounted) or by reducing the ability to count (e.g. if startled newts move too quickly and an accurate count cannot be undertaken). The use of ultraviolet-a light may reduce these disturbance effects and may improve the detection of male great crested newts since the white tail flash may reflect UV light.

To test this hypothesis, the author visited a pond in North Lanarkshire, Scotland on the evening of the 15 April 2017 at approximately $21: 30 \mathrm{~h}$. The pond surface was c. $450 \mathrm{~m}^{2}$ and between $200 \mathrm{~mm}$ and $500 \mathrm{~mm}$ deep within $1 \mathrm{~m}$ of the shoreline. Surveyors wore yellow-lensed protective glasses and used a WolfWill WW-UVL-0019 LED blacklight torch, peak light emission frequency of $395 \mathrm{~nm}$ (UV-A), to illuminate the pond following the methodology of Griffiths et al. (1996). Immediately after this, the pond was illuminated using the same basic methodology but instead with a standard LED spotlamp (Clulite Clubman CB3 1,000,000 candlepower). Newts were identified using key ID features visible in torchlight (Mclnerny \& Minting, 2016) and the number of newts counted under both lighting conditions was compared. The sample with the ultraviolet light did not reveal any newts as particulate matter within the water column was illuminated by the ultraviolet light and thus penetration of the water column by the light was reduced. However, the pass with the standard LED spotlamp was successful as an unquantified number of great crested newts of both sexes as well as smooth and palmate newts were observed.

In this instance, ultraviolet light did not reveal any newts as particulate matter within the water column refracted UV-A light more than it did white light. However, this failure may have been due to pond-specific conditions and it may be worth testing the UV-A torch in a variety of ponds and in a variety of environmental conditions. Additionally, there may be value in extending the testing to UV-B and infrared torches to reduce the disturbance to great crested newts from torchlight sampling and achieve more accurate counts (e.g. Buchanan, 1993; Baker \& Richardson, 2006).

\section{ACKNOWLEDGEMENTS}

With thanks to an anonymous reviewer and V. Muir for their comments on this manuscript, and to G. Sennhauser for his assistance with fieldwork.

\section{REFERENCES}

Baker, B.J. \& Richardson, J.M.L. (2006). The effect of artificial light on male breeding-season behaviour in green frogs, Rana clamitans melanota. Canadian Journal of Zoology 84: 1528-1532.

Buchanan, B.W. (1993). Effects of enhanced lighting on the behaviour of nocturnal frogs. Animal Behaviour 45: 893899.

English Nature. (2001). Great Crested Newt Mitigation Guidelines. Natural England, Peterborough. 75 pp.

Griffiths, R.A., Raper, S.J. \& Brady, L.D. (1996). Evaluation of a standard method for surveying common frogs (Rana temporaria) and newts (Triturus cristatus, T. helveticus, and T. vulgaris). JNCC Report no. 259. 1996. 29 pp.

Kröpfli, M., Heer, P. \& Pellet, J. (2010). Cost-effectiveness of two monitoring strategies for the great crested newt (Triturus cristatus). Amphibia-Reptilia 31: 403-410.

Accepted: 16 April 2019 